\title{
Effect of low-temperature surface hardening by carburization on the fatigue behavior of AISI 316L austenitic stainless steel
}

Peng, Yawei; Liu, Zhe; Chen, Chaoming; Gong, Jianming; Somers, Marcel A. J.

Published in:

Materials Science and Engineering A

Link to article, DOI:

10.1016/j.msea.2019.138524

Publication date:

2020

Document Version

Peer reviewed version

Link back to DTU Orbit

Citation (APA):

Peng, Y., Liu, Z., Chen, C., Gong, J., \& Somers, M. A. J. (2020). Effect of low-temperature surface hardening by carburization on the fatigue behavior of AISI $316 \mathrm{~L}$ austenitic stainless steel. Materials Science and Engineering $A, 769$, [138524]. https://doi.org/10.1016/j.msea.2019.138524

\section{General rights}

Copyright and moral rights for the publications made accessible in the public portal are retained by the authors and/or other copyright owners and it is a condition of accessing publications that users recognise and abide by the legal requirements associated with these rights.

- Users may download and print one copy of any publication from the public portal for the purpose of private study or research.

- You may not further distribute the material or use it for any profit-making activity or commercial gain

- You may freely distribute the URL identifying the publication in the public portal 
Effect of low-temperature surface hardening by carburization on the fatigue behavior of

\title{
AISI 316L austenitic stainless steel
}

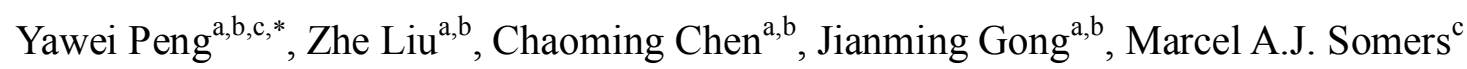

${ }^{\mathrm{a}}$ School of Mechanical and Power Engineering, Nanjing Tech University, No.30 Puzhu South Road, Nanjing 211816, China

${ }^{\mathrm{b}}$ Jiangsu Key Lab of Design and Manufacture of Extreme Pressure Equipment, No.30 Puzhu South Road, Nanjing 211816, China

${ }^{\mathrm{c}}$ Department of Mechanical Engineering, Technical University of Denmark, Produktionstorvet b. 425,2800 Kgs. Lyngby, Denmark

\begin{abstract}
The influence of low-temperature gaseous carburization on the fatigue behavior of AISI 316L austenitic stainless steel was investigated. Tension-compression axial fatigue tests were performed under ambient conditions on untreated and carburized AISI 316L. The results show that the carburized AISI $316 \mathrm{~L}$ has a $22 \%$ higher endurance limit compared to untreated AISI 316L. Fractography investigations with scanning electron microscope (SEM) reveal that for the untreated AISI 316L fatigue cracks initiate at the surface regardless of the applied stress level. For the carburized AISI 316L fatigue cracks initiate at the surface for relatively high-level stresses; for relatively low-level stresses fatigue cracks initiate at inclusions beyond the carburized case. After carburization, the ductility in the outmost $10 \mu \mathrm{m}$ of the carburized case has significantly reduced, leading to micro-crack occurrence during fatigue tests and associated relaxation of compressive residual stress in this region. Beyond this surface-adjacent region, no evident stress relaxation occurs due to the enhanced yield strength

${ }^{*}$ Corresponding author. Tel: +86 25 58139361; fax: +86 2558139361

E-mail addresses: pengyw@njtech.edu.cn (Y. Peng)
\end{abstract}


of the carburized case. The enhanced fatigue performance is mainly ascribed to the compressive residual compressive stress profile introduced by the carbon-concentration profile over the case. Moreover, solid solution strengthening by interstitially dissolved carbon contributes to improve the fatigue performance.

Keywords: Austenitic stainless steel; Low-temperature carburization; Fatigue behavior; Residual stress relaxation 


\section{Introduction}

Austenitic stainless steels (AUSSs) are widely applied due to their good integrity performance and excellent corrosion resistance. However, their low surface hardness and strength result in modest tribological and fatigue properties as compared to other alloys and limits their use in applications subject to fatigue and wear (in combination with corrosion). Therefore, it is of great importance to improve the surface hardness and strength of AUSSs.

Thermochemical surface engineering is an effective technology to improve the surface hardness and strength of steels [1]. Low-temperature surface hardening (LTSH) by

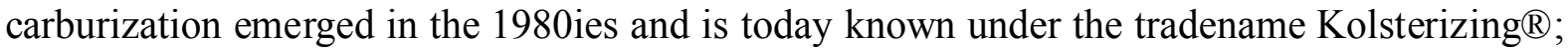
in the last 20 years also gaseous equivalents were developed [2-4]. LTSH by carburization produces a carbon-concentration depth profile, the case. Solid solution strengthening by carbon enhances the yield strength and the hardness over the case and improves the wear performance significantly, without compromising the original corrosion resistance (the corrosion performance can even be improved) [5-10]. After low-temperature carburization, the elasto-plastic accommodation of the carbon-induced lattice expansion results in compressive residual stresses of up to several GPa's in the surface hardened case $[11,12]$. It is anticipated that the compressive residual stresses introduced by surface treatments can enhance the fatigue resistance of AUSSs [13-15]. Tokaji et al. [16] studied the fatigue behavior of low-temperature carburized AISI 316 under rotating bending fatigue conditions and found that the carburized steels exhibit a considerably higher fatigue strength compared to the untreated material. Comparison of a thick case with a thin case shows longer time to failure, but the endurance limits are the same and enhance by $30 \%$ with respect to the endurance limit of the untreated material. Axial fatigue tests of low-temperature carburized 
AISI 316L were conducted by Agarwal et al. [17]. They also found that the fatigue performance is significantly enhanced, but no further improvement is observed after additional carburization cycles, suggesting that the improved fatigue performance is independent of case depth. Actually, the published works mostly focus on comparing the fatigue properties of the carburized and untreated materials. Detailed investigations of crack initiation and the stability of carburization-induced compressive residual stresses during cyclic loading are required for a better understanding of the fatigue mechanism in the low-temperature carburized AUSSs. The residual stresses retained in the material after a certain number of cycles under the cyclic loading play a more critical role in the fatigue performance than the initially present compressive residual stresses introduced by surface engineering [18-20].

In the present work, the fatigue behavior of low-temperature gaseous carburized AISI 316L under tension-compression fatigue condition was investigated and the fatigue mechanisms were revealed. In order to clarify the role of compressive residual stresses in enhanced fatigue performance, the relaxation behavior of carburization-induced compressive residual stresses under cyclic loading was also studied.

\section{Material and experimental procedures}

\subsection{Material and specimens}

The investigated material is the commercial type AISI 316L plate with $12 \mathrm{~mm}$ thickness in solution-annealed state. The chemical composition of the steel is (in wt.\%): $\mathrm{C} 0.025, \mathrm{Si}$ 0.481, Mn 1.16, Ni 10.24, Cr 16.97, Mo 2.00 and Fe balance.

Uniaxial tensile specimens with gauge geometry $\Phi 5 \times 20 \mathrm{~mm}^{2}$ according to ASTM E8/E8M [21] were cut with their tensile direction parallel to the rolling direction. 
Fig.1 gives the dimensions of the fatigue specimen, in accordance with ASTM E466 [22]. All fatigue specimens were cut with their loading axis parallel to the rolling direction.

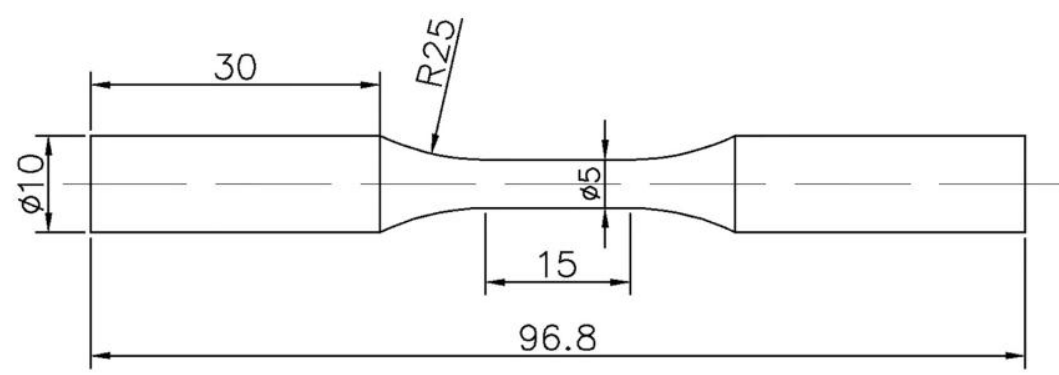

Fig.1. Dimensions of the fatigue specimen (unit: $\mathrm{mm}$ ).

\subsection{LTSH treatment}

After machining, a selection of specimens was surface hardened. LTSH treatment includes two steps, one step for surface activation and another for gaseous carburization. The carburization step was performed at $470{ }^{\circ} \mathrm{C}$ in a $\mathrm{CO}, \mathrm{H}_{2}$ and $\mathrm{N}_{2}$ gas mixture for $30 \mathrm{~h}$. Before carburization, the surfaces of all specimens were ground with emery papers down to grid 1200 . The treatment used in this study was described in detail in previous work [4].

\subsection{Uniaxial tensile test}

Uniaxial tensile tests were performed on a servo-hydraulic testing machine (SHIMADZU, EHF-EV101K2-020-1A) at ambient temperature. For the first $30 \%$ engineering strain, the strain rate was $6.7 \times 10^{-4} \mathrm{~s}^{-1}$ and controlled by a contacting extensometer. Thereafter, the tensile specimen was tested at a rate of $1.5 \mathrm{~mm} / \mathrm{min}$ without extensometer.

\subsection{Fatigue test and residual stress relaxation test}

Tension-compression fatigue tests were conducted on the same servo-hydraulic testing machine at ambient temperature under stress-control mode with the zero mean stress $(R=-1)$ and a frequency of $15 \mathrm{~Hz}$.

In order to study the stability of compressive residual stresses introduced by the 
carburizing treatment during fatigue tests, stress relaxation tests of the carburized specimens were performed on the servo-hydraulic testing machine with preset fixed cyclic loading cycles. After the tests, the residual stresses along the loading direction were measured on a PROTO-iXRD residual stress analyzer (see section 2.5).

\subsection{Characterization of specimen}

The cross-sectional microstructure of the carburized specimens was studied by optical microscopy (AXIO Imager.Alm), after grinding, polishing and etching in oxalic acid. The carbon concentration-depth profile were quantified by line analysis with a Shimadzu electron probe micro-analyzer EPMA-1610 [4]. The hardness-depth profile was obtained on the cross-section of the carburized specimen by nano-indentation tests with a Berkovich indenter under $12 \mathrm{mN}$ indentation load on a Hysitron Triboindenter Ti-Premier. The loading, holding and unloading times were $5 \mathrm{~s}, 2 \mathrm{~s}$ and $5 \mathrm{~s}$, respectively. Residual stresses were determined by the PROTO-iXRD residual stress analyzer using the $\sin ^{2} \psi$ method with $\mathrm{Mn} \mathrm{K}_{\alpha}$ X-radiation $(\lambda$ $=0.210314 \mathrm{~nm})$. For depth profiling, thin layers were successively removed by electropolishing. More details about the residual stress measurements in this study were described in previous work [13]. The fracture surface topography of the fractured tensile specimens and fatigue specimens was investigated on a JSM-6360 scanning electron microscope (SEM).

\section{Results and Interpretation}

\subsection{Characterization of carburized specimen}

A cross-sectional micrograph of low-temperature carburized AISI 316L is given in Fig. 2. The carburized case appears as a featureless 30 - $\mu$ m-thick zone, while the substrate has a characteristic austenite structure. The different etching behaviors of case and unaffected steel 
indicate that the corrosion resistance of the carburized case is better than that of the substrate in oxalic acid.

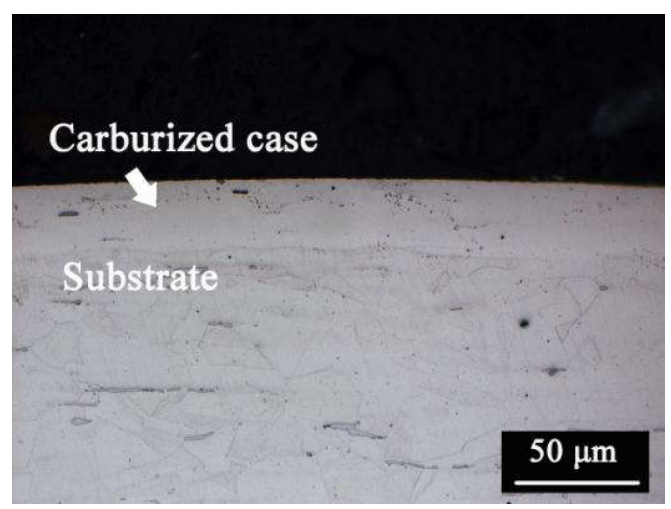

Fig. 2. Cross-sectional microstructure of low-temperature carburized AISI $316 L$.

Fig. 3 gives the carbon concentration-depth profile of low-temperature carburized AISI 316L. After carburization, the carbon concentration reaches 2.8 wt. $\%$ at the surface and decreases monotonically with depth. The increased carbon concentration depth is about $30 \mu \mathrm{m}$, which is consistent with the case depth established by the microstructure characterization shown in Fig. 2.

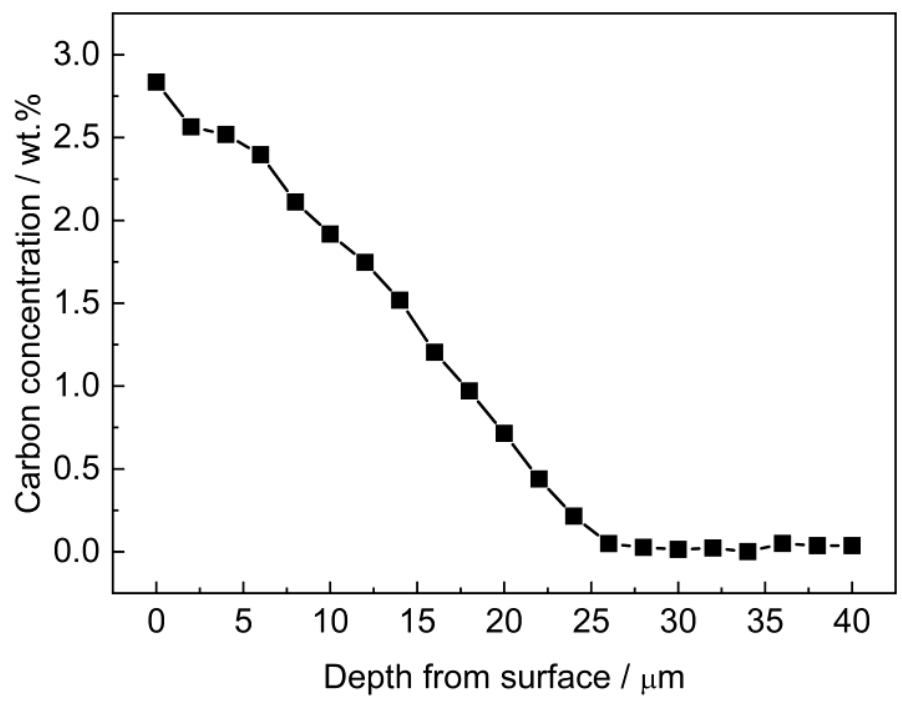

Fig. 3. Carbon concentration-depth profile of low-temperature carburized AISI 316L.

The hardness-depth and compressive residual stress-depth profiles of low-temperature carburized AISI 316L are given in Fig. 4. The hardness shows the same trend as the carbon concentration profile; a maximum value of $11 \mathrm{GPa}$ is attained near the surface (see Fig. 4 top). 
Such large hardness cannot be obtained by mechanical surface treatments like surface rolling [14] and shot peening [23]. After low-temperature carburization, a maximum compressive residual stress of $2.5 \mathrm{GPa}$ is obtained at the surface (see Fig. 4 bottom). As the yield stress of stainless steel is far below this value, the strength of the surface region must have been significantly improved by low-temperature carburization. Actually, a competition between strengthening by carbon dissolution and composition-induced compressive residual stresses during low-temperature carburization eventually has led to plastic deformation in the part of the carburized case with high carbon content. This is demonstrated with the observation of extensive slip bands at the carburized specimen surface region (the outer $10 \mu \mathrm{m}$ ) [5].

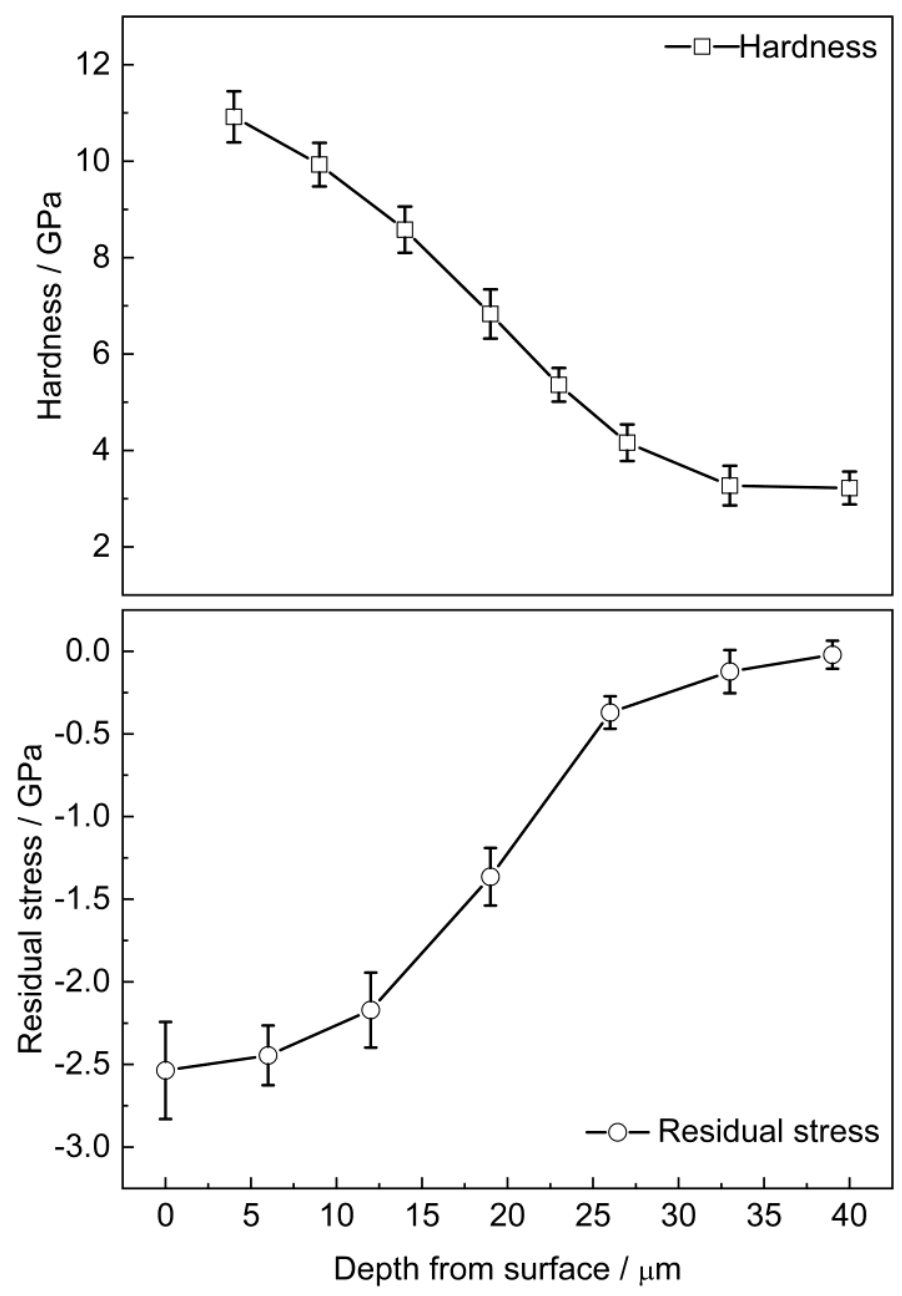

Fig. 4. Hardness-depth (top) and residual stress-depth (bottom) profiles of low-temperature carburized AISI 316 L. 


\subsection{Tensile testing results}

Uniaxial tensile engineering-stress vs. engineering strain curves of the untreated and carburized specimens are shown in Fig. 5. In comparison with the untreated specimen, the determined yield strength $(0.2 \%$ offset $)$ in the carburized specimen is slightly lower, $275 \mathrm{MPa}$ instead of $292 \mathrm{MPa}$, while the ultimate tensile strength is slightly higher, $650 \mathrm{MPa}$ as compared to $635 \mathrm{MPa}$. After carburization, the elongation of the specimen at fracture has slightly reduced.

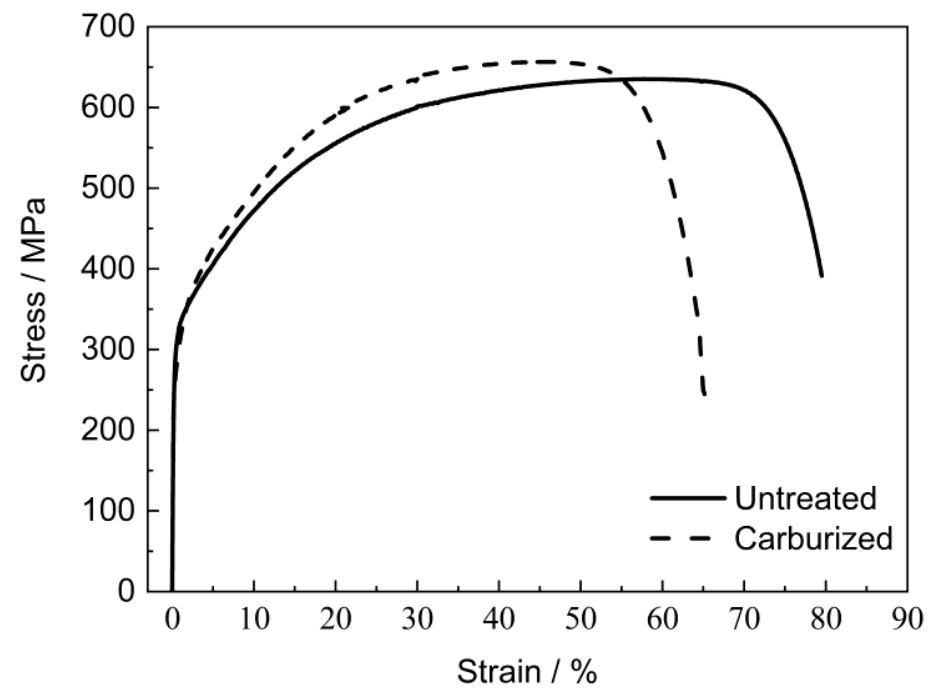

Fig. 5. Engineering stress vs. engineering strain curves of AISI 316L before and after

\section{low-temperature carburization.}

Fig. 6 shows SEM fractographs of the untreated and carburized specimens after uniaxial tensile tests. From the overall view (see Figs. 5a and c), the necking appears more pronounced in the untreated specimen, which is consistent with a slight loss in ductility upon carburizing. The surface of carburized specimen shows crevices in the necking region, pointing at brittle fracture in the surface-adjacent part. From the detailed view (see Figs. 5b and d), dimples, characteristic for ductile fracture, are observed in the untreated specimen. For the carburized specimen, the fracture topography in the region of the carburized case differs distinctly from the untreated specimen. Close to the surface of the carburized case, a brittle fracture 
topography is observed. With increasing distance to the surface, tiny dimples appear in the carburized case, suggesting that the ductility of the carburized case decreased with increasing carbon concentration.
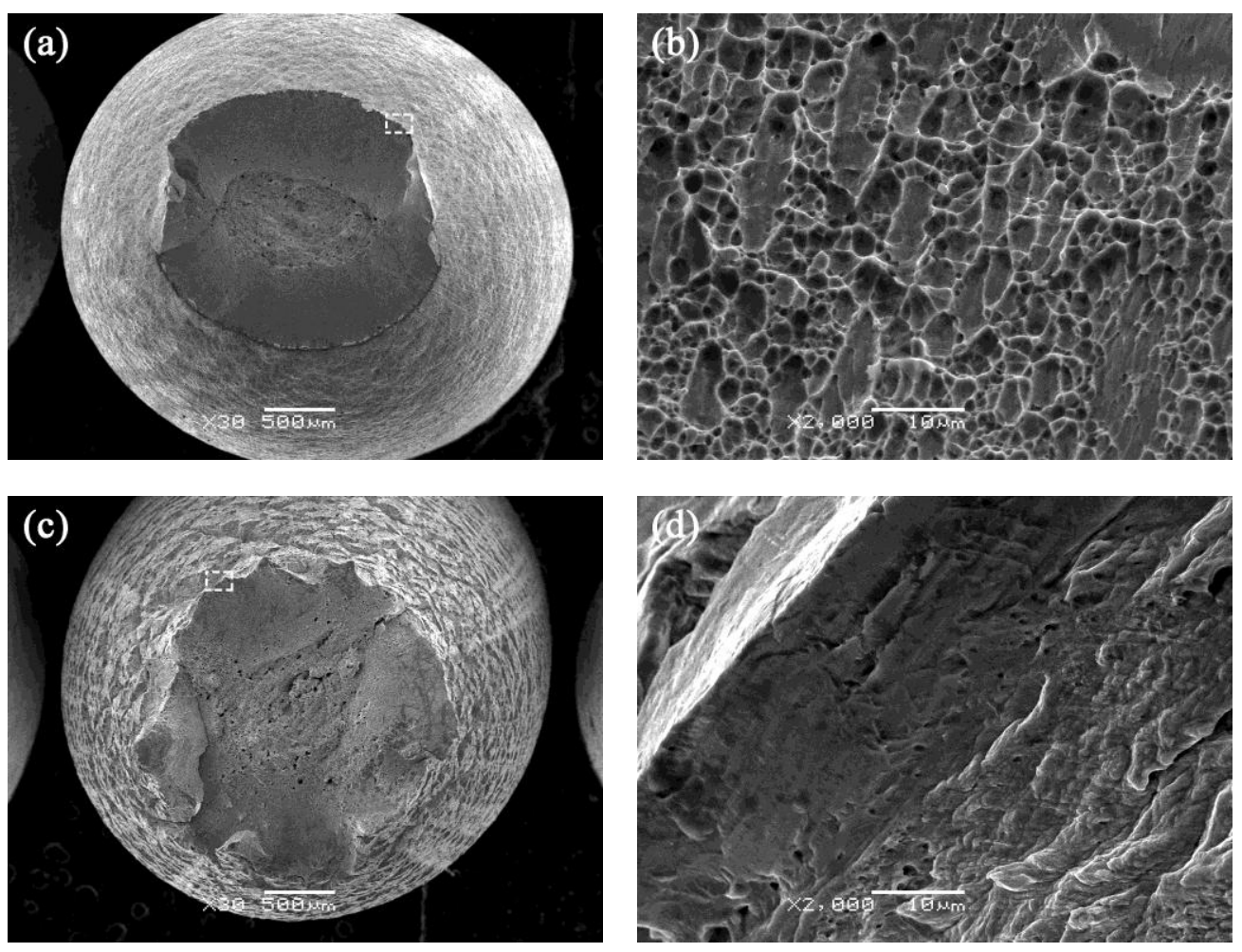

Fig. 6. SEM fractographs of AISI 316L after uniaxial tensile testing: (a) overall view,

untreated, (b) detail view, untreated, (c) overall view, carburized, (d) detail view, carburized.

\subsection{Fatigue testing results}

The fatigue $S-N$ curves of the untreated and carburized AISI 316L are given in Fig. 7.

The fatigue performance of the carburized specimens is enhanced considerably compared to the untreated specimens. The endurance limits of the untreated specimens and the carburized specimens are $225 \mathrm{MPa}$ and $275 \mathrm{MPa}$, respectively, corresponding to a $22 \%$ improvement. 


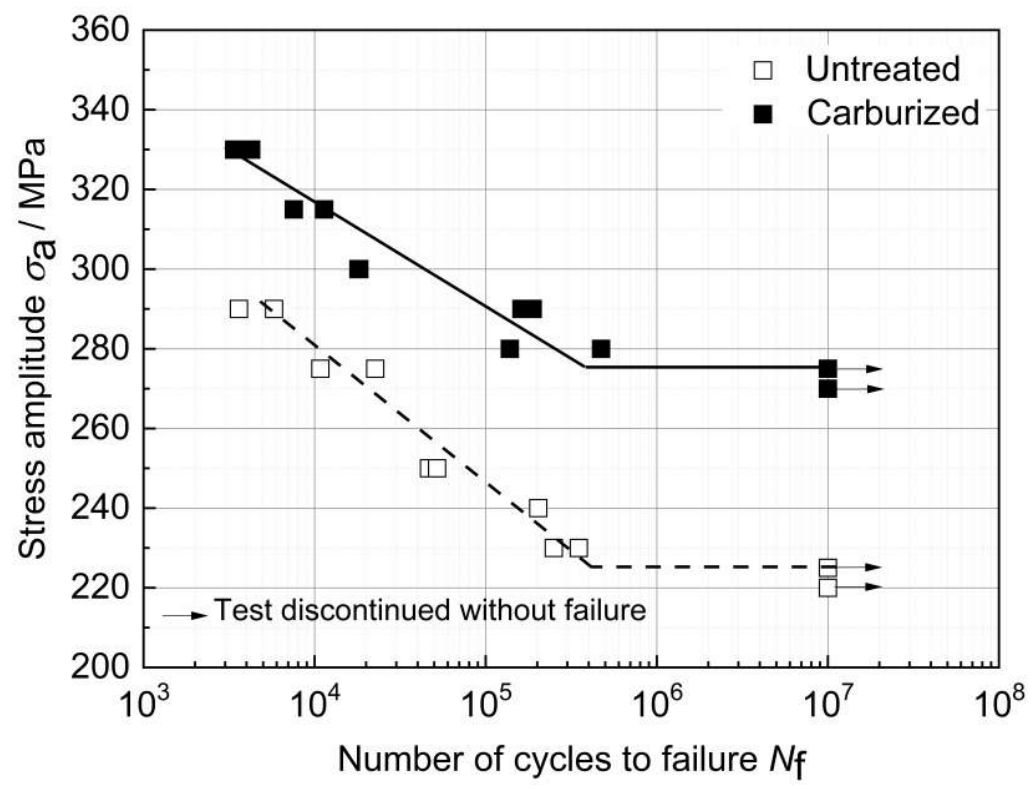

Fig. 7. S-N curves of AISI $316 \mathrm{~L}$ before and after low-temperature carburization.

SEM fractographs of untreated AISI 316L after fatigue testing are given in Fig. 8. From the overall views (see Figs. 8a and d), no necking is observed and the typical fatigue fracture morphologies such as shell patterns in the fast fracture region can be observed. In Fig. 8b and $8 \mathrm{e}$, the fatigue crack initiation sites are located at the surface of the specimen, regardless of the applied stress level. For lower applied stress level, the numbers of the crack initiation sites and the distances of the fatigue striation (compare Figs. 8c and f) decrease. 

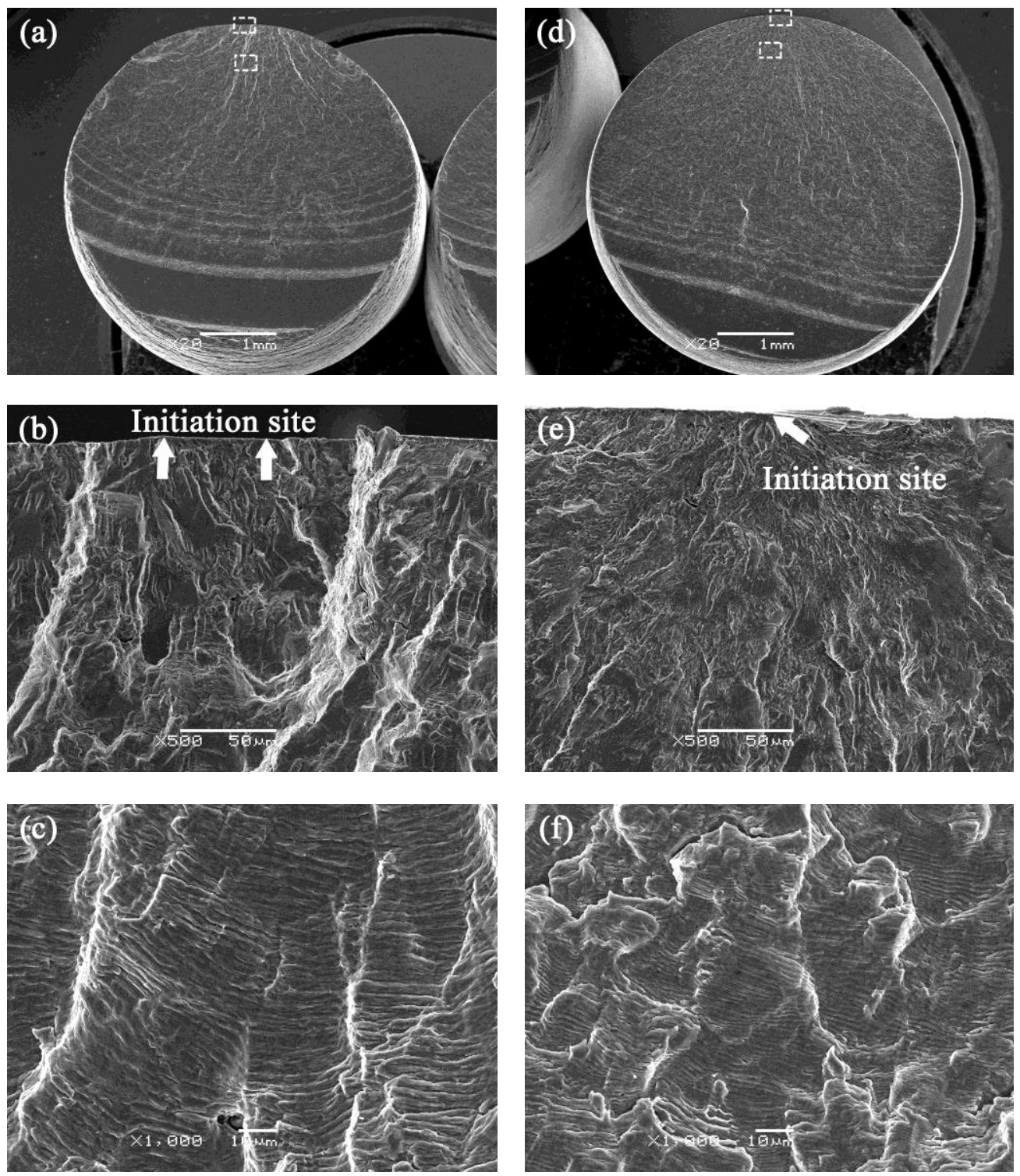

Fig. 8. SEM fractographs of untreated AISI $316 \mathrm{~L}$ after fatigue testing: (a) overall view, $\sigma_{a}=$ $290 \mathrm{MPa}$, (b) initiation site, $\sigma_{a}=290 \mathrm{MPa}$, (c) fatigue striation, $\sigma_{a}=290 \mathrm{MPa}$, (d) overall view, $\sigma_{a}=240 \mathrm{MPa}$, (e) initiation site, $\sigma_{a}=240 \mathrm{MPa}$, (f) fatigue striation, $\sigma_{a}=240 \mathrm{MPa}$.

SEM fractographs of carburized AISI 316L after fatigue testing under relatively high-level stresses are shown in Fig. 9. For applied stresses equal or beyond $300 \mathrm{MPa}$, crack initiation sites in the carburized specimens are at the specimen surface, analogous to the untreated specimens. Enlarging the area of the crack initiation site in Fig. 9b, it is observed that cracks are present along grain boundaries and slip bands in the region of the outermost 10 $\mu \mathrm{m}$ carburized case (see Fig. 9e). 

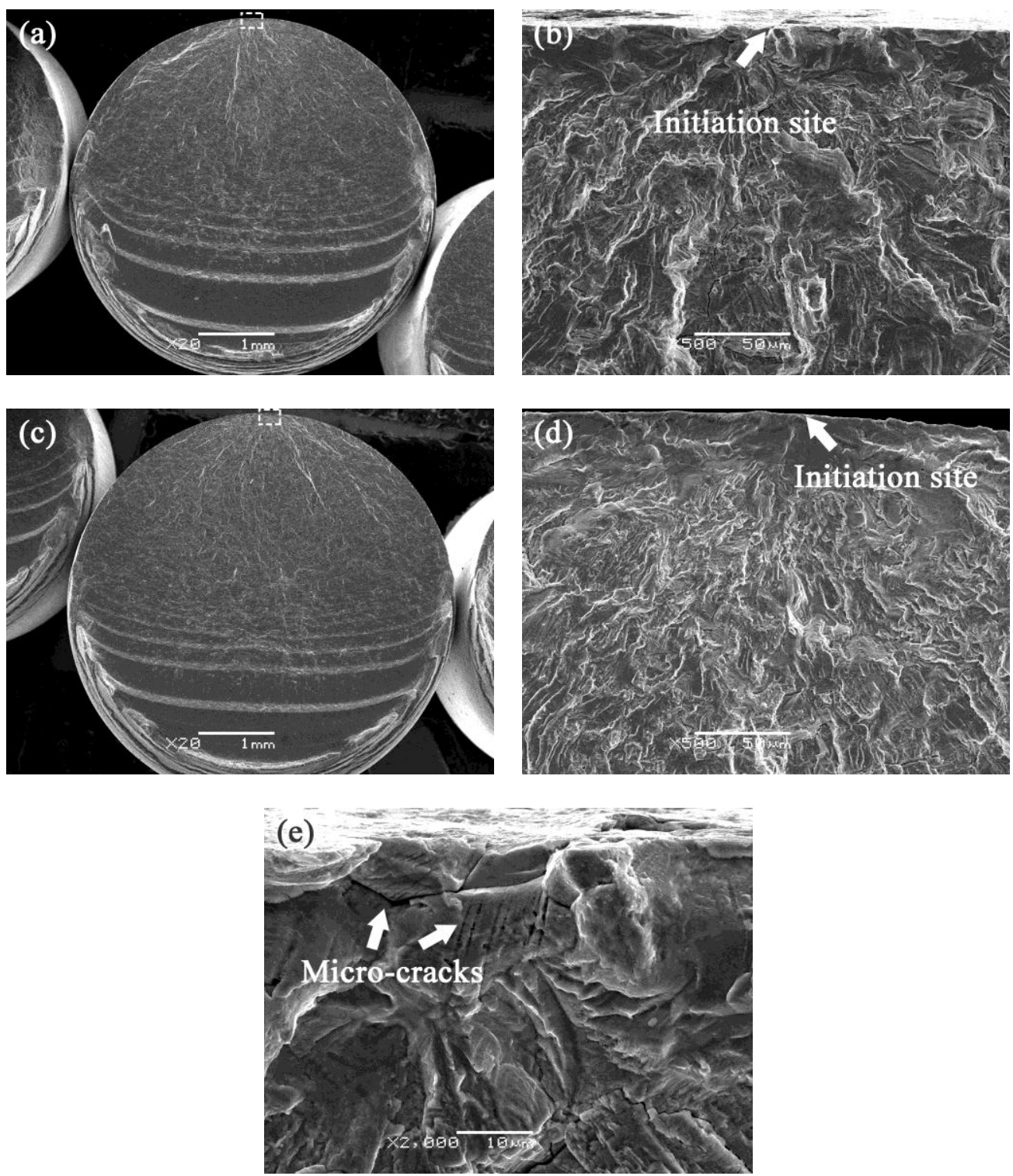

Fig. 9. SEM fractographs of carburized AISI 316L after fatigue testing: (a) overall view, $\sigma_{a}=$ $315 \mathrm{MPa}$, (b) initiation site, $\sigma_{a}=315 \mathrm{MPa}$, (c) overall view, $\sigma_{a}=300 \mathrm{MPa}$, (d) initiation site,

$$
\sigma_{a}=300 \mathrm{MPa} \text {, (e) detail view of (b). }
$$

For relatively low applied stresses, i.e. below $300 \mathrm{MPa}$, the fractographs of carburized AISI 316L after fatigue testing are shown in Fig. 10. Fish-eye like patterns are observed (see Figs. 10a and $\mathrm{b}$ ), implying that crack initiation away from the surface occurs. A close examination reveals that fatigue cracks initiate at inclusions, which were identified as silicates with energy-dispersive X-ray spectroscope (EDS). As observed in Fig. 10d, cracks are present within the inclusion and along the interface between inclusion and matrix. 

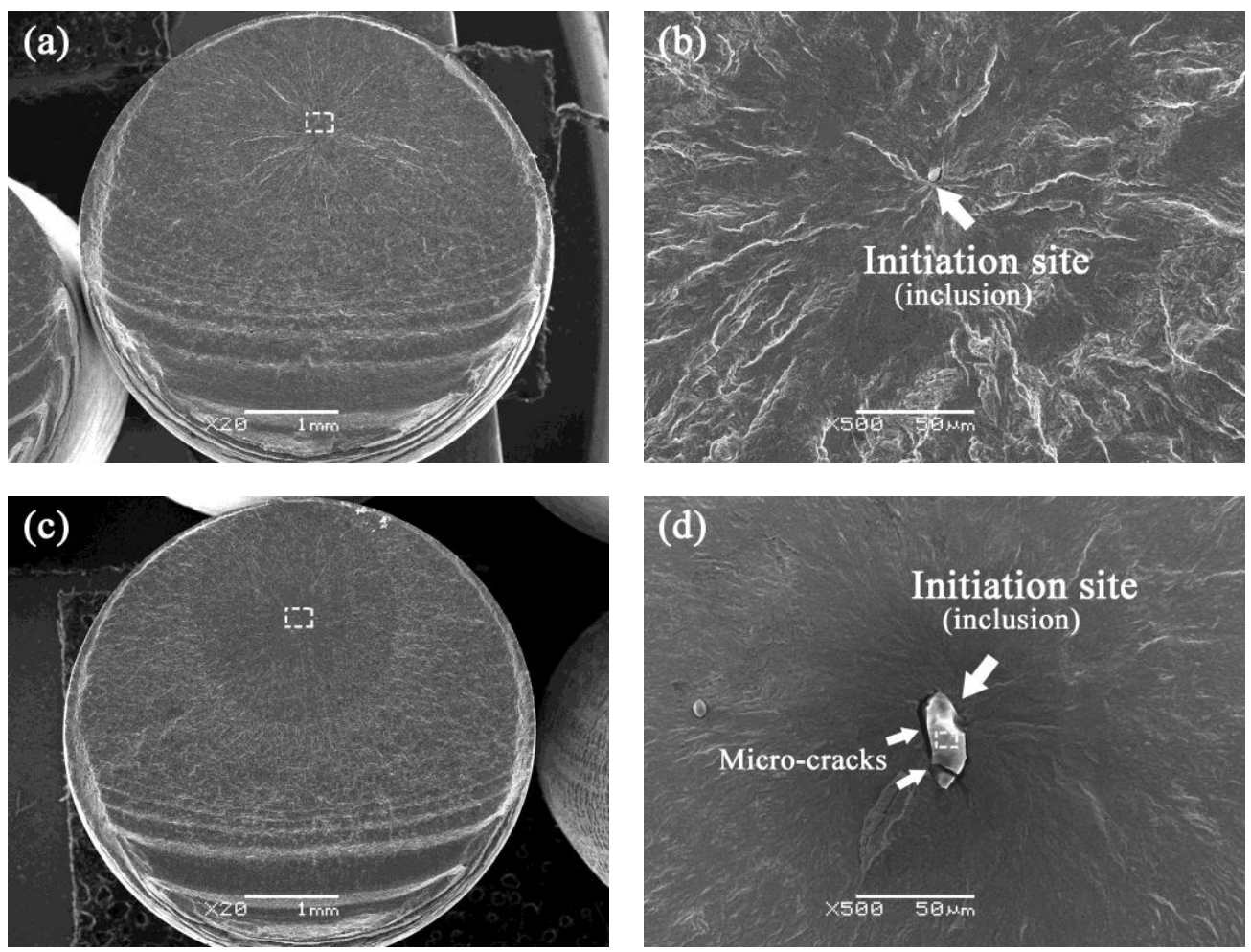

(e)

ca

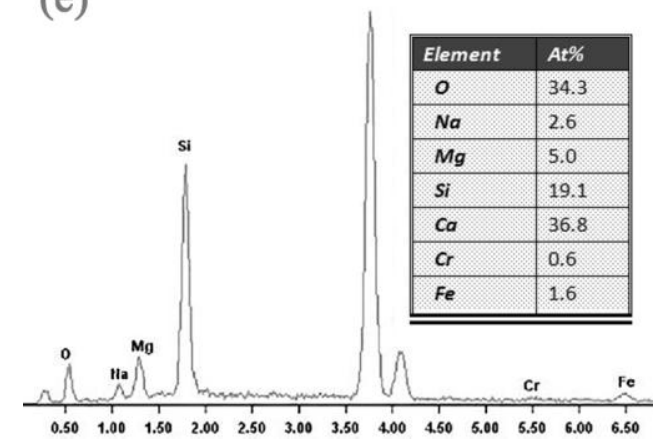

Fig.10. SEM fractographs of carburized AISI 316L after fatigue testing: (a) overall view, $\sigma_{a}=$ $290 \mathrm{MPa}$, (b) initiation site, $\sigma_{a}=290 \mathrm{MPa}$, (c) overall view, $\sigma_{a}=280 \mathrm{MPa}$, (d) initiation site,

$$
\sigma_{a}=280 \mathrm{MPa},(\mathrm{e}) \text { EDS of inclusion in (d). }
$$

3.4. Relaxation of residual stress under cyclic loading

Fig.11 gives the normalized surface residual stresses of the carburized specimens after different numbers of loading cycles. Evidently, the values of the surface compressive residual stresses hardly change within the first $10^{3}$ cycles, which means that the carburization-induced compressive residual stresses are stable during the fatigue tests. For a cycle number beyond the critical value a sudden reduction of the surface compressive residual stresses occur, 
whereafter they largely remain unchanged until failure. The onset of the sudden decline in compressive residual stresses depends on the alternating load; a higher load leads to earlier decline. After relaxation, the as-determined, i.e. uncorrected, retained surface compressive residual stresses are still beyond $60 \%$ of the original values. Considering the accuracy of the measurements, the retained compressive residual stress values after the decline are independent of the applied stress level. It is noted that the measured surface compressive residual stresses during the stress relaxation tests were not corrected for the variation in information depth with tilt angle $\psi[24,25]$ (such a correction would require the entire depth profile of residual stresses). This means there are artifacts in the determined stress values, so-called ghost stresses [25]. The composition gradient is the, by far, dominating source of, and is therefore not expected to change during fatigue tests. Consequently, omission of a correction for variation of information depth with tilt is not expected to have a large influence on the observed trend in Fig. 11.

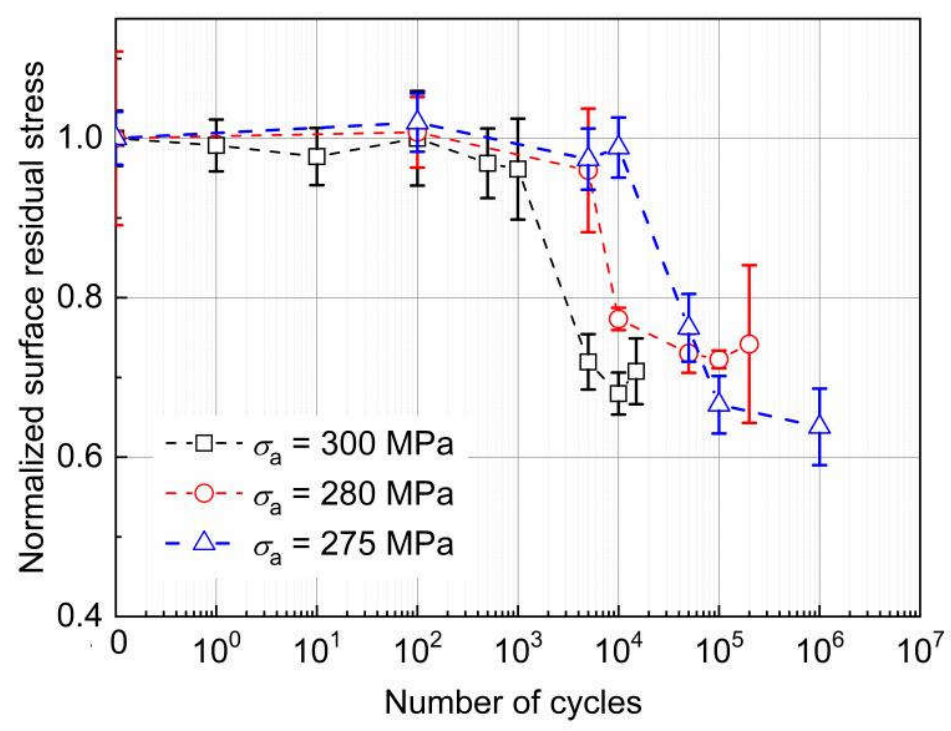

Fig. 11. Normalized surface residual stresses of carburized fatigue specimens after different number of loading cycles. 


\section{Discussion}

\subsection{Residual stress relaxation}

Conventionally, the relaxation of the surface compressive residual stresses introduced by mechanical surface treatments like deep rolling [19] or laser penning [26] are successively lower and mainly take place during the first cycle followed by incrementally reducing changes during further cyclic loading. Interestingly, the compressive residual stresses introduced by low-temperature carburization appear to be more stable under the cyclic loading than those induced by deep rolling or laser penning. In order to further investigate the relaxation behavior of the carburization-induced compressive residual stresses under cyclic loading, residual stress-depth profiles were determined (see Fig. 12). Interestingly, residual stress relaxation is only evident in the first $10 \mu \mathrm{m}$ of the carburized case, regardless of the applied stress level. Generally, the reason for residual stress relaxation under the cyclic loading is local plastic deformation as a consequence of exceeding the local yield strength. However, since the strength of the surface region is significantly enhanced after low-temperature carburization and additional plastic deformation, is not expected in the carburized case for the applied stress level. Actually, the more pronounced solid solution strengthening towards the surface region is likely to be associated with a reduction in ductility. Jiang et al. [5] found that the cracking strain at the surface of a carburized case is only about $1.4 \%$. Furthermore, there is no evident plastic deformation when the surface cracks. The observation of micro-cracks along grain boundaries and shear bands (see Fig. 9e) in the outer $10 \mu \mathrm{m}$ coincides with the depth range of stress relaxation. Hence, brittle fracture is held responsible for a reduction of residual stresses in this region. 


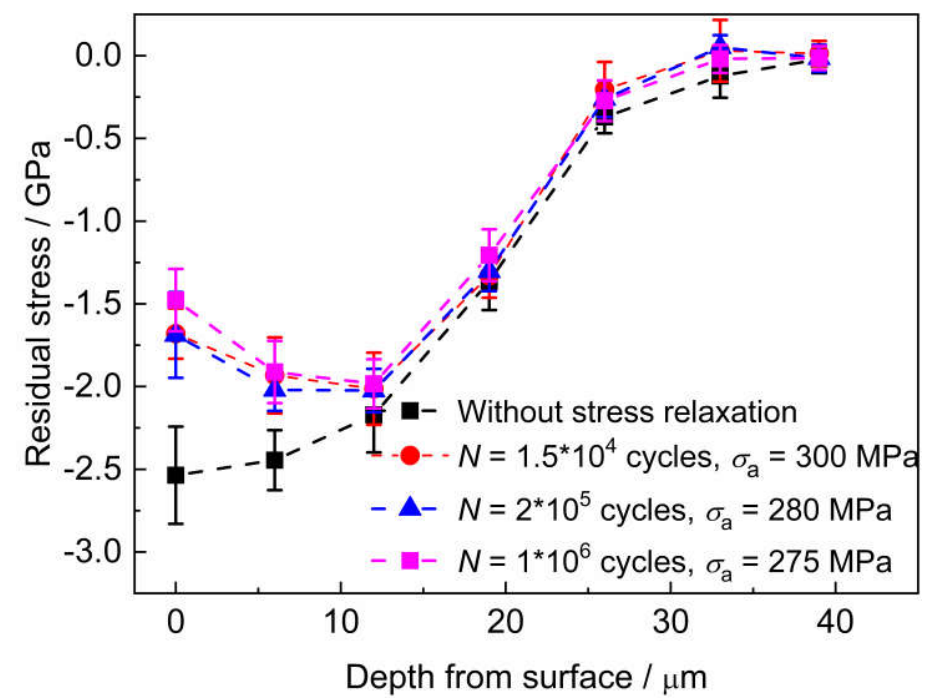

Fig.12. Residual stress depth-profiles of carburized fatigue specimens after different number of loading cycles

\subsection{Fatigue fracture mechanism}

After low-temperature carburization, the fatigue life of AISI $316 \mathrm{~L}$ is significantly enhanced, while the endurance limit increases $22 \%$. Based on the experimental results, the fatigue behaviors of the untreated and carburized specimens are discussed. The fatigue fracture mechanisms of the untreated and carburized specimens are illustrated in Fig. 13.

For the untreated specimens, fatigue cracks initiate at the surface of the specimens regardless of the applied stress level (see Fig. 13a). The reason is, that the highest stress level occurs at the surface, where the slip bands undertaking plastic deformation are more easily formed under the cyclic loading. The pre-existence of slip bands provided a favorable condition for fatigue crack initiation [27]. For example, stress concentrations always occur at grooves or scratches introduced by surface machining. Even for perfectly smooth, defect-free surfaces, stress concentrations can still be highest near the surface. The reason for this is the stress state experienced by the individual grains in the polycrystalline austenitic steel, which is both elastically and plastically anisotropic. Grains in the interior are constrained by the surrounding, neighbouring grains and therefore experience a tri-axial state of stress. Grains 
adjacent to the surface are only constrained by the grains deeper in the material and therefore experience stress gradients and a biaxial state of stress at the very surface. The number of slip systems activated in "surface" grains is smaller than in "bulk" grains, wherefore plastic deformation is easier in the former. For this reason, fatigue cracks in the untreated specimens always initiate from the surface, whereafter they propagate towards the interior until failure.

For the carburized specimens that were fatigue tested at relatively high-level stresses, the fatigue fracture mechanism is illustrated in Fig. 13b. The crack initiation sites in the carburized specimens are still located at the surface, but a significant improvement of the fatigue performance is obtained. Conventionally, crack initiation and early stage crack propagation are significantly influenced by the plastic strain field. After low-temperature carburization, substantial contents of interstitial carbon atoms are dissolved in the surface region. The resistance to local plastic deformation is enhanced as a result of solid-solution strengthening by the interstitially dissolved carbon atoms. This has led to a higher stability of the residual stress state under cyclic loading. Moreover, the formation of stress concentrators for crack initiation is suppressed by carburization-induced compressive residual stresses. However, owing to the brittle nature of the outmost part of the carburized case, micro-cracks develop along grain boundaries and carburization-induced slip bands under the cyclic loading after a certain cycles, leading to partial relaxation of the compressive residual stress in this region. The retained compressive residual stresses ahead of the crack tip act as crack closure stresses. Thus, the enhanced yield strength and compressive residual stresses in the carburized case reduce the driving force for fatigue crack initiation and propagation in the carburized case.

For the carburized specimens that were fatigue tested at relatively low-level stresses, the 
fatigue fracture mechanism is schematically illustrated in Fig. 13c. Evidently, the compressive residual stresses in the carburized case are sufficiently large to prevent propagation of the cracks that have developed in the brittle outer part. This is consistent with observations by Hsu et al. [28], who found that the fatigue crack growth threshold stress intensity in AISI 316L increases after low-temperature carburization. Instead fatigue cracks nucleate at the locations of internal stress concentrators, such as brittle inclusions, not experiencing compressive residual stresses from the carburized case. Under cyclic loading, de-bonding of the interface between inclusion and matrix and fracture of the inclusion occurs, which provide the sites for fatigue crack initiation. This leads to delayed crack initiation and thus much higher fatigue life.

(a)

(b)

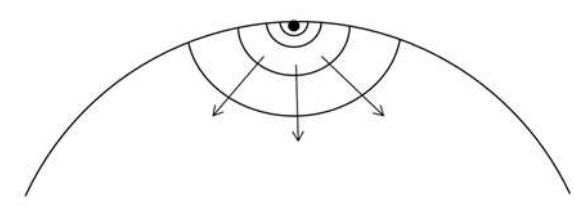

Cracks along the slip band Cracks along the grain boundary

Carburized case
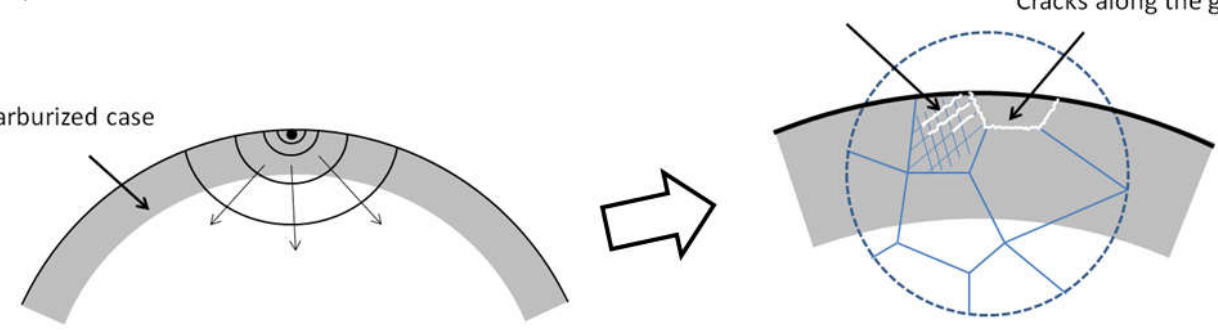

(c)
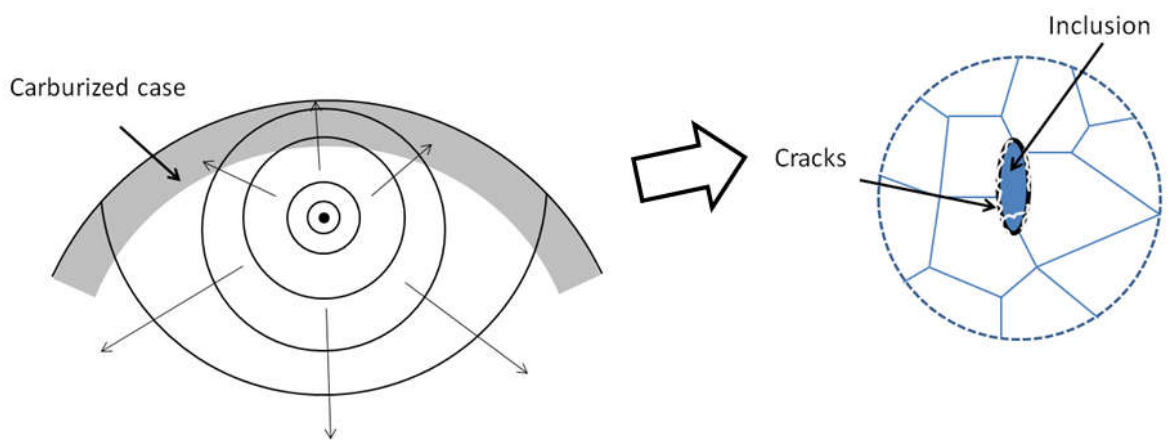

- Fatigue crack initiation site

Fig. 13. Schematic diagram of fatigue fracture mechanisms of AISI 316L: (a) untreated specimen, (b) carburized specimen under relatively high-level stresses, (c) carburized specimen under relatively low-level stresses. 


\section{Conclusions}

The effect of low-temperature gaseous carburization on tension-compression fatigue behavior of AISI 316L was investigated. The main conclusions are as follows:

(1) Low-temperature surface carburization can significantly improve the fatigue performance of AISI $316 \mathrm{~L}$, and leads to a $22 \%$ increase in endurance limit.

(2) For the untreated specimens, fatigue cracks initiate at the specimen surface, regardless of the applied stress level. For the carburized specimens, the location of fatigue crack initiation changes from the surface for relatively high-level stresses to the interior for relatively low-level stresses.

(3) The outmost $10 \mu \mathrm{m}$ of the carburized case is brittle and develops micro-cracks under cyclic loading, leading to partial relaxation of compressive residual stresses in this region. No evident stress relaxation occurs in the remaining part of the carburized case because of the considerably enhanced strength.

(4) Fatigue crack initiation is suppressed by solid-solution strengthening in the carburized case and carburization-induced compressive residual stresses. Compressive residual stresses have a dominant beneficial effect on the fatigue performance.

\section{Acknowledgements}

The work is supported by National Natural Science Foundation of China (No.51475224 and No.51975272), Natural Science Foundation of Jiangsu Higher Education Institutions of China (No.14KJA470002).

\section{Data availability}

The raw/processed data required to reproduce these findings cannot be shared at this time as the data also forms part of an ongoing study. 


\section{Reference}

[1] E.J. Mittemeijer, M.A.J. Somers, Thermochemical surface engineering of steels, WoodHead Publishing, Amsterdam, 2015.

[2] G.M. Michal, F. Ernst, H. Kahn, Y. Cao, F. Oba, N. Agarwal, A.H. Heuer, Carbon supersaturation due to paraequilibrium carburization: Stainless steels with greatly improved mechanical properties, Acta Mater. 54 (2006) 1597-1606.

[3] T.L. Christiansen, T.S. Hummelshøj, M.A.J. Somers, Gaseous carburising of self-passivating $\mathrm{Fe}-\mathrm{Cr}-\mathrm{Ni}$ alloys in acetylene-hydrogen mixtures, Surf. Eng. 27 (2011) 602-608

[4] Y. Peng, J. Gong, Y. Jiang, M. Fu, D. Rong, The effect of plastic pre-strain on low-temperature surface carburization of AISI 304 austenitic stainless steel, Surf. Coat. Technol. 304 (2016) 16-22.

[5] Y. Jiang, Y. Li, Y. Jia, X. Zhang, J. Gong, Gradient elastic-plastic properties of expanded austenite layer in 3161 stainless steel, Acta Metall. Sin-Engl. 90 (2018) 1-11.

[6] F. Rotundo, L. Ceschini, C. Martini, R. Montanari, A. Varone, High temperature tribological behaviour and microstructural modifications of the low-temperature carburised AISI 316L austenitic stainless steel, Surf. Coat. Tech. 258 (2014) 772-781.

[7] L. Ceschini, C. Chiavari, E. Lanzoni, C. Martini, Low-temperature carburised AISI 316L austenitic stainless steel: Wear and corrosion behavior, Mate. Design 38 (2012) 154-160.

[8] W. Niu, R.S. Lillard, Z. Li, F. Ernst, Properties of the passive film formed on interstitially hardened AISI 316L stainless steel, Electrochim. Acta 176 (2015) 410-419.

[9] Y. Peng, C. Chen, X. Li, J. Gong, Y. Jiang, Z. Liu, Effect of low-temperature surface carburization on stress corrosion cracking of AISI 304 austenitic stainless steel, Surf. Coat. Tech. 328 (2017) 420-427.

[10] S.C. Gallo, H. Dong, EBSD and AFM observations of the microstructural changes induced by low temperature plasma carburising on AISI 316, Appl. Surf. Sci. 258 (2011) 608-613.

[11] T.S. Hummelshøj, T.L. Christiansen, M.A.J. Somers, Lattice expansion of carbon-stabilized expanded austenite, Scripta Mater. 63 (2010) 761-763.

[12] Y. Peng, Z. Liu, Y. Jiang, B. Wang, J. Gong, M.A.J. Somers, Experimental and numerical analysis of residual stress in carbon-stabilized expanded austenite, Scripta Mater. 157 (2018) 106-109.

[13] E.S Puchi-Cabrera, M.H Staia, E.A Ochoa-Pérez, D.G. Teer, Y.Y. Santana-Méndez, J.G. La Barbera-Sosa, D. Chicot, J. Lesage, Fatigue behavior of a 316L stainless steel coated with a DLC film deposited by PVD magnetron sputter ion plating, Mater. Sci. Eng. A 527 (2010) 498-508.

[14] H.W Huang, Z.B Wang, J. Lu, K. Lu, Fatigue behaviors of AISI 316L stainless steel with a gradient nanostructured surface layer, Acta Mater. 87 (2015) 150-160. 
[15] J. Zhou, Z. Sun, P. Kanouté, D. Retraint, Effect of surface mechanical attrition treatment on low cycle fatigue properties of an austenitic stainless steel, Int. J. Fatigue 103 (2017) 309-317.

[16] K. Tokaji, K. Kohyama, M.Akita, Fatigue behaviour and fracture mechanism of a 316 stainless steel hardened by carburizing, Int. J. Fatigue 26 (2004) 543-551.

[17] N. Agarwal, H. Kahn, A. Avishai, G. Michal, F. Ernst, A.H. Heuer, Enhanced fatigue resistance in $316 \mathrm{~L}$ austenitic stainless steel due to low-temperature paraequilibrium carburization, Acta Mater. 55 (2007) 5572-5580.

[18] W.Z. Zhuang, G. R. Halford. Investigation of residual stress relaxation under cyclic load, Int. J. Fatigue 23 (2001) 31-37.

[19] I. Nikitin, M. Besel. Correlation between residual stress and plastic strain amplitude during low cycle fatigue of mechanically surface treated austenitic stainless steel AISI 304 and ferritic-pearlitic steel SAE 1045, Mater. Sci. Eng. A 491 (2008) 297-303.

[20] K. Dalaei, B. Karlsson, L.E. Svensson, Stability of shot peening induced residual stresses and their influence on fatigue lifetime, Mater. Sci. Eng. A 528 (2011) 1008-1015.

[21] ASTM, E8/E8M, Standard test methods for tension testing of metallic materials, 2016a.

[22] ASTM, E466, Standard practice for conducting force controlled constant amplitude axial fatigue tests of metallic materials, 2015.

[23] S. Bagherifard, S. Slawik, I. Fernández-Pariente, C. Pauly, F. Mücklich, M. Guagliano, Nanoscale surface modification of AISI 316L stainless steel by severe shot peening, Mater. Design 102 (2016) 68-77.

[24] M.A.J Somers, E.J. Mittemeijer, Development and relaxation of stress in surface layers; Composition and residual stress profiles in $\gamma^{\prime}$-Fe4N1-x, layers on $\alpha$-Fe substrates, Metall. Trans. A 21 A(1990) 189-204.

[25] T. Christiansen, M.A.J. Somers, Avoiding ghost stress on reconstruction of stress- and composition-depth profiles from destructive X-ray diffraction depth profiling, Mater. Sci. Eng. A 424 (2006) 181-189.

[26] Y. Sano, K. Akita, K. Takeda, R. Sumiya, R. Tazawa, T. Saito, C. Narazaki, Stability of residual stress induced by laser peening under cyclic mechanical loading, Int. J. Struct. Integrity 2 (2011) 42-50.

[27] K.S. Chan, Roles of microstructure in fatigue crack initiation, Int. J. Fatigue 32 (2010) 1428-1447.

[28] J.-P. Hsu, D. Wang, H. Kahn, F. Ernst, G.M. Michal, A.H. Heuer, Fatigue crack growth in interstitially hardened AISI 316L stainless steel, Int. J. Fatigue 47 (2013) 100-105. 